\title{
E-Learning and Further Education: How do Individual Learning Paths support Personal Learning Processes
}

\author{
Bertil Haack, Peter Koppatz, Margit Scholl, Frank Sistenich, Ulrike Tippe \\ Technische Fachhochschule Wildau (TFHW) / University of Applied Sciences Wildau (UASW) \\ Bahnhofstraße, 15745 Wildau, Germany
}

\begin{abstract}
The MOPEM project includes two fixed scenarios that have been defined to convey the idea of "learning paths". Our aim in this paper is to demonstrate the contexts and conditions for flexible learning paths that can be tailored to meet individual needs. The concept of this kind of specialised path is to enable learners to individualise the learning process and to adjust it to their personal needs. We will outline the background and provide examples to explain the concept of learning stations which we use in our four courses: Online Marketing, CRM Systems, Business Communications and Event Marketing. This idea of "freely" combining subject matter naturally leads to the question of multi-applicability for the learning blocks in various educational contexts. The answers to this question are interesting not only in terms of the feasibility of learning paths from a content and didactic point of view, but also with regard to the economic viability of E-Learning or Blended Learning Systems, which ultimately require technical implementation. In addition we will present some first thoughts on the design of a prototype "Content Pool". It would, however, only make sense to develop and implement this within the scope of a follow-up project.
\end{abstract}

Keywords: learning Paths, multi-applicability, learning process, E-Learning, Blended Learning

\section{BACKGROUND}

The MOPEM project ("Marketing On-line - Path to Enter new Markets") was initiated by the Polish banking and educational institution TEB Education Corporation based in Poznań [1]. It focuses among other things on the idea of "learning paths". These are specific courses (here in the area of advanced marketing) that any MOPEM user can put together for him / herself using the entire MOPEM range to tailor the course to his / her own requirements. Examples are given within the project to illustrate the idea using two clearly defined learning paths. We believe that it would pay to discuss the use of learning paths in more detail. This would provide the opportunity to lay out their didactic possibilities, demonstrate their current limitations and offer some initial remarks on how a flexible prototype could be developed, which it would then make sense to implement as part of a follow-up project.

With learning paths, the student is given the chance to put together the course content and create a study schedule that fits as snugly as possible with his / her own learning needs or job demands. This idea of "freely" combining subject matter naturally leads to the question of multi-applicability for the learning blocks in various educational contexts. At the same time the concept of certification could be extended to allow for an individually-designed further education programme streamlined to the particular person's lifestyle and sensitive to their body of prior knowledge and to their specific objectives in seeking certification. It is important to clarify how the blocks of an ELearning or Blended Learning course should be designed so that a meaningful range of specific learning paths can be constructed from them. The prospect of technical implementation in the future means that any relevant standards should be tested and further developed where necessary.

The answers to this question of multi-applicability are interesting not only in terms of the feasibility of learning paths but also with regard to the economic viability of E-Learning or Blended Learning Systems. Learning paths are based on the reusability of E-Learning blocks and one may reasonably assume that ELearning or Blended Learning courses can be designed and implemented along more cost-effective lines than would otherwise be possible. In order for this idea to be put into practice using the concept of learning paths, attention needs to be paid to various key areas that are themselves involved in a dynamic interplay: here content, pedagogic / didactic, sociological and technical aspects are involved and these must be sufficiently well-designed so as to stand up in the business or economic context.

The four dimensions are aspects of various perspectives which are all either connected to or dependent on each other. They should thus be considered together as a kind of musical quartet where all the instruments must be tuned to one another [2]. We take this kind of holistic approach in another EU project called COMBLE (Community of Integrated Blended Learning in Europe) [3]. In this paper our focus is primarily on the content and the pedagogic / didactic levels, since these have precedence over the other two areas. Learning paths need to make sense and be feasible both didactically speaking and in terms of content otherwise questions about their technical implementation and any use they may have in the student-teacher working relationship are meaningless. In terms of content it is important that the individual teaching modules in a learning path are capable of being strung together seamlessly without creating gaps in content - the modules need to build on each other in a logical way. Besides looking at these aspects we would also like to offer some initial thoughts on the possibilities for technical implementation. These should be examined and developed fully in a future research project.

\section{DIDACTIC CONSIDERATIONS WITH REGARD TO “LEARNING PATHS” IN THE MOPEM PROJECT}

The MOPEM project has its origins in the perceived lack of online training opportunities in the field of advanced marketing and has set itself the goal of developing modules that are suited to both professionals and students and can be used on a variety of learning platforms. The courses on advanced marketing for European markets should draw on case studies and practical examples to highlight cultural differences, and be built around discrete modules that are reusable and stand independently of 
the educational system. In this way they may be used by any educational provider while taking into the account the needs of companies active in the market.

The concept of specialisation paths of this kind enables course participants to individualise their learning process and to adjust it to meet their personal needs. The MOPEM project offers a model definition of two specifically prescribed learning paths running through the courses and learning modules that have been developed. Learning scenarios are also provided. Within MOPEM it was not our plan to design flexible individualised learning paths, as that would have exceeded the budget. However we feel that in a follow-up project, it is precisely these kinds of paths that could provide a solution to the training problems that businesses and institutions are facing. Education is nowadays taken as a fourth production factor alongside natural, capital and labour resources. This poses the question of how learning environments should be designed to take into account the ever more rapid lifestyle and workplace changes that are taking place around us. This goes hand in hand with the continuous integration of training into working life, its tailoring to suit the different life phases (life-long learning) and the move towards more self-directed learning processes.

This change of perspective - away from the institutionalised transmission of knowledge and in the direction of independent acquisition of knowledge and competencies - is often coupled with the concept of management. Some key words here are knowledge management, self-management, information management etc., which are ever more closely linked to traditional autodidactic learning. This development is supported by the theory of (radical) constructivism. The constructivist approach has a number of interesting facets which have a bearing on the issue of adult didactics and adult pedagogics - for example, the idea that adults do not like to be taught or instructed. They literally have minds of their own and their own individual ways of learning, and as a result they evaluate explanations in very different ways: one person will refuse to understand and reject what is said, while another may find in it the long sought-after illumination that finally makes a subject comprehensible. Learning processes are non-linear processes, which work with back referencing and generate new knowledge with the help of the old. Siebert [4] calls this "hooked-up learning" where adults constantly latch on to whatever they have learnt earlier in life and develop a partiality for subjects that are important for them and appear meaningful for their future. Thus in techniques designed to reduce material [5], the "anchor terms" are spoken of as detailing in a specialist map - from these the student can immediately see and identify the contexts and focuses for learning. Instead of maps one speaks nowadays of building up an advanced organiser [6] which gives learners a visual overview of the subject matter within which they can place themselves according to their level of experience [7].

The constructivist model also integrates the individual character of the learning process whereby the learner handles his / her subject matter with a high degree of independence. In combination with online methods and tools this can lead to striking outcomes, especially in the area of adult education. It is in this sense that constructivist ideas are incorporated into the MOPEM project and implemented in the design and use of learning paths.

Within the MOPEM project there is general agreement that all modules should have independent status and thus serve as stand-alone solutions with each one representing a meaningful learning unit in its own right. Moreover all the modules are conceived in such a way that they can be integrated in a Blending Learning concept. The constructivist aspect also plays a central role allowing learners to navigate a learning path in line with their individual level of knowledge. Thus a learning path represents a special form of station learning, a method familiar from classroom teaching in schools [8]. Learning paths can be simply distinguished from one another according to whether a determined sequence of stations or learning direction is provided for or whether learners can make their own specific choice from the stations put at their disposal. Figure 1 puts the basic questions surrounding the flexible management of learning paths in a clear schematic form. In order to use a "downstream" component (Content 5 in the figure), one must first fulfil the technical requirements for the "upstream" components (Contents 1 and 2 in the figure).

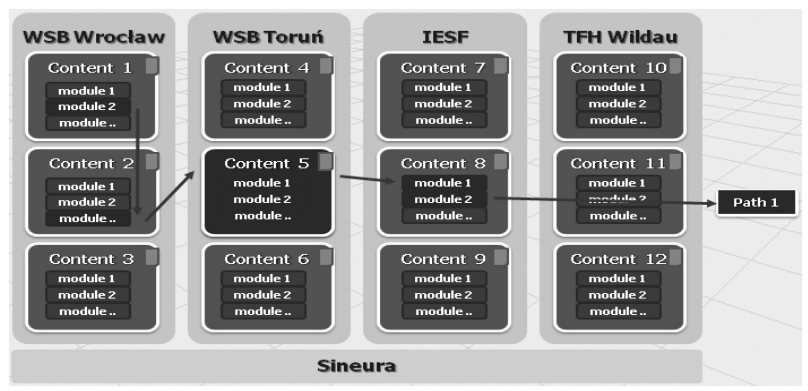

Fig. 1 Schematic representation of the definition of a learning path using single modules or a whole course offered by the partners involved in the MOPEM project (figure taken from the project proposal and interim report)

In essence the components in a learning path must follow on from one another in such a way that a "downstream" component can only be a station on a learning path if the learner brings along all the prerequisites needed to successfully work through this component. From a technical point of view, in the flexible management of learning paths, such didactic and content-based conditions must be capable of being applied on a variety of platforms.

\section{INDIVIDUAL LEARNING PATHS BASED ON THE EXAMPLE OF THE CRM SYSTEMS AND ONLINE MARKETING COURSES}

In this project the amount of content and number of partners involved made it seem too complex to simply set learners on their way and have them define their paths independently. In order to provide a reasonable transition from one subject to the next, it is necessary not only to calibrate the technical levels, and the specialist terminology and definitions used but also to arrange the content in such a way there are no duplications and contradictions (viz. the remarks above). In the following section we aim, independently of the two fixed learning paths laid down in MOPEM, to show further possible learning paths on the basis of courses developed by the UASW. The constructivist approaches described above were used in designing our courses to help formulate the didactic dimension and with an eye to the issue of practical implementation. This approach is especially fruitful when it is not a question of simply "funnelling" factual knowledge according to the principle of "drill and practice", but rather of promoting independent, self-defined learning. 
We will now go into further detail to illustrate one sample course: Customer Relationship Management Systems (CRM Systems). The E-Learning course Online Marketing is made up of the following modules:

- What is Online Marketing?

- Banner Advertising

- Affiliate Marketing

- E-Mail Marketing

- Keyword Advertising

- Search Machine Optimisation

- Online Marketing with Web 2.0

These modules can be combined with other modules of other MOPEM courses.

Our course Customer Relationship Management Systems consists of the modules:

- Introduction (Fundamentals and Aims of CRM)

- Technology and Functions

- Conception and design of CRM Systems

- CRM Projects

The modules in the CRM Systems course build on one another and are thus not quite so independent of each other. On the other hand, there is no requirement to work through all the modules, i.e. work through all sub-sections of all learning stations. For instance, it would be sufficient for an initial overview to limit oneself to the first two modules (learning stations). At this point let us take another look at the idea of learning paths. So far with the two courses mentioned there are a total of seven modules on offer, which can be worked on either alone or in a study group, depending on the learning environment. There are now a whole host of individual learning paths possible. A perfectly logical route would be, for example, when a student at first decides to learn the essentials of CRM systems but then finds that the subject of online marketing - which in terms of content is not so far removed - is more interesting. He / she then abandons some modules and lays out the following learning path:

(1) Fundamentals and Aims of CRM (from the CRM Systems course)

(2) Technology and Functions (from CRM)

(3) Affiliate Marketing (from Online Marketing)

(4) Online Marketing with Web 2.0 (from Online Marketing)

The above learning path combines four learning stations. However, not all the sub-sections must be worked through. Within the framework of the two courses presented here, there are further combinations and learning paths possible owing to the variability of the Online Marketing course. As a result one can say that the idea of self-defined learning is already a practical proposition here.

\section{INDIVIDUAL LEARNING PATHS BASED ON TH SAMPLE COURSE BUSINESS COMMUNICATIONS}

The course CRM Systems was used above as model with regard to its structuring and integration of learning paths. In this chapter we present one further course, Business Communications. We would like in this chapter to look at the reasoning behind the selection of course material and use examples to illustrate and justify our choices. In selecting and conceiving marketing modules that go beyond the classical marketing training ${ }^{1}$ using the framework of a Blended Learning System designed to work with individual learning paths, one must take into proper account the current state of the markets, which are, moreover, constantly shifting. The marketing know-how that is to be transmitted and developed in the learning process requires an understanding of the fundamentals of the subject, which should form a solid basis of knowledge in terms of marketing strategy and marketing tools. Against this background of basic knowledge, new subject matter must be accessible to lead the course participant on to the next level.

With regard to the needs of the target group it is important for the course design that as a rule most of the learners come from SME (small and medium enterprises). In the growth processes of the last years and decades it is precisely these companies that have struggled to build a sophisticated communications policy at any rate what they managed was clearly less than was possible (and usual) for large-scale enterprises. SME are traditionally bound chiefly to product and pricing policy outlooks - areas where nowadays competitive advantages are practically nonexistent.

One should also remember that a classic communications mix as it is traditionally taught (consisting of tools from advertising, public relations, sales promotions and personal selling) has developed considerably in the last years - this is, of course, reflected in the basic knowledge that our course participants have. Thus the variety of tool mixes has changed as has the structure of communication. The strongest structural change can be seen in the fact that classical communication channelled through the mass media has been supplemented by new tools of dialogue-based, interactive communication. Modern concepts of communications policy activate recipients on the conative level, which means that the recipient becomes an actor and is incorporated in an interactive function in brand and business communication. Communication between businesses and customers / recipients exclusively based on a classical, monologue-based structure is no longer enough to achieve ongoing market success. For this reason further courses are devoted to business communications. The single modules (learning stations) are so designed that sub-sections can be selected, learning aims defined and user instructions formulated. Besides also in this course the modules can be combined with different modules also of other courses ("learning path").

\section{TECHNICAL ASPECT: THE MOPEM CONTENT POOL}

Within the framework of the MOPEM project courses have been developed by all the partners involved. The courses will be made available to all the partners in the project for their own use and re-use - and for possible reworking - and will be put up on the individual learning platforms. The SCORM [9] standard was chosen as the data exchange format. Other exchange formats (e.g. HTML or PDF) should also be provided together with the original content. Courses and modules are mostly sent out by E-mail using classical data exchange processes such as packed ZIP files. In this way they can be made available to the other project partners. However, mail exchanges have serious disadvantages. For this reason the UAS Wildau has tried in this

1 All MOPEM's courses have "extended marketing" as their aim. 
project to find alternative options and to demonstrate these conceptually as model pilot solutions. According to our understanding of the problem, the processes described below represent a suitable approach to finding a solution. We have taken as a starting point the question of how in general to organise the exchange and development of course material. An answer to this question should fulfil the following criteria. It should allow for:

- the possibility of notification in case of new or altered content

- the search for suitable course material

- the parallel development of a course by different authors

- the compiling of new courses from existing materials

- the description of courses by using of metadata with search potential

- a course to be discussed

- the author to be informed of mistakes or suggestions

and have:

- an appropriate filing system for the course material

To maximise the effectiveness of the working process, a decision was made to use existing software. In this way the solutions currently available in software development were explored with an eye to administering the course material. Starting with the best known version control systems we placed the following products on our short list:

- Bazaar (http://bazaar-vcs.org/)

- Subversion (http://subversion.tigris.org/)

- Git (http://git.or.cz/)

While Bazaar and GIT are designed for a distributed application, Subversion uses a centralised approach. A deciding factor was the existence of easily installable client software for the systems mentioned. Unfortunately at present only Subversion satisfactorily fulfils this last criterion. It has the further advantage that it can be combined with the bug-tracking and wiki system Trac [10].

Unfortunately not all metadata can be brought together in a SCORM manifest and if no SCORM format is supported or desired, there is no general metadata format. We see the SCORM 2.0 initiative as a very promising solution, which seeks to further develop existing standards for the new demands of ELearning and Blended Learning. Before we go on we would like to refer you once more to the most important points of criticism levelled at the existing SCORM standard [11].

\section{SUMMARY OF APPROACHES TO REUSING MOD- ULES TO CREATE FLEXIBLE, INDICIDUAL LEARN- ING PATHS}

The MOPEM project demonstrates that the idea of learning paths is fundamentally workable. Provided that the E-Learning blocks are appropriately designed on the content, didactic/ pedagogic, technical and sociological levels, it is then possible to assemble them in different combinations and thus construct learning paths that are oriented to the needs of the individual students and can support their learning process. Beyond establishing this general sense of feasibility (which was the scope of the MOPEM project) the question arises, however, of which conditions must be fulfilled and what aids should be used to create the simplest, most multi-facetted, most individually adaptable learning paths within an E-Learning or Blended Learning System.

The concrete answer to the question posed above comes in two stages: First we will consider the breakdown of the educational processes into sequences according to the IMS Learning Design. Then we will continue the discussion using a metaphor taken from the world of theatre.

The IMS Learning Design takes as its starting point a so-called "didactic situation": "Those involved in the educational process undertake acts of learning and teaching in the roles of student and instructor using the resources offered by the learning environment and directed towards certain learning objectives." [12]. This didactic situation has a specified sequence which can in turn be comprised of sequential sections. This corresponds to an act in a play which can be composed of several scenes. At the end of an act all the participants (teacher and student) need to be in sync so that there can be a transition to the next act. This synchronisation ultimately takes place on the content level: The student must fulfil all requirements at the end of an act in order to be able to move on to the next act.

Educational processes can be seen as hierarchical learning sequences and educational steps, which each proceed in the same way as the IPO model from information technology:

Input $\rightarrow$ Processing $\rightarrow$ Output

It is important to bear in mind:

a) that learner competencies count as learning prerequisites and are thus mandatory inputs for a learning step (the learning step can only be successfully completed when the student has the necessary competencies as an entry requirement and applies them to the learning step), and

b) that extended learner competencies are rated as learning step outcomes and thus count as output.

With these additional ideas taken on board, this means that a learning step can be started (i.e. joined on to previously completed scenes or acts) with a reasonable prospect of success if the outputs of the previous learning steps, scenes or acts provide the minimum competencies which the student needs as input for the next step, as illustrated in fig. 2. The learning path concept thus requires that, at the beginning of an act or scene within a learning path, all the preceding acts or scenes on this path taken together must deliver the minimum requirements to enable the student to make a meaningful switch to the particular act or scene they plan to embark on.

This rule represents a key design proviso for the development of reusable E-Learning or Blended Learning blocks that can be built into learning paths and thus provide E-Learning or

Blended Learning solutions. These then enable users to create any number of logical learning paths. However this proviso also makes explicit something that was already implicit in the learning path idea: The design of E-Learning and Blended Learning components is a problem of quantity. An enormous number of E-Learning or Blended Learning blocks may be required - and these must be in operation prior to a learning unit (an "act") - to provide the relevant prerequisites. By the same token, many acts may lead, according to the rules of combinatorics, to a huge and 
possibly confusing number of learning paths. The synchronisation points mentioned above can only be of limited assistance here. Admittedly educational activities may be studiously completed and all prerequisites (learner competencies), so to speak, knitted together to enable the next learning steps; yet there may be many different learning paths that can lead to any one of these synchronisation points.

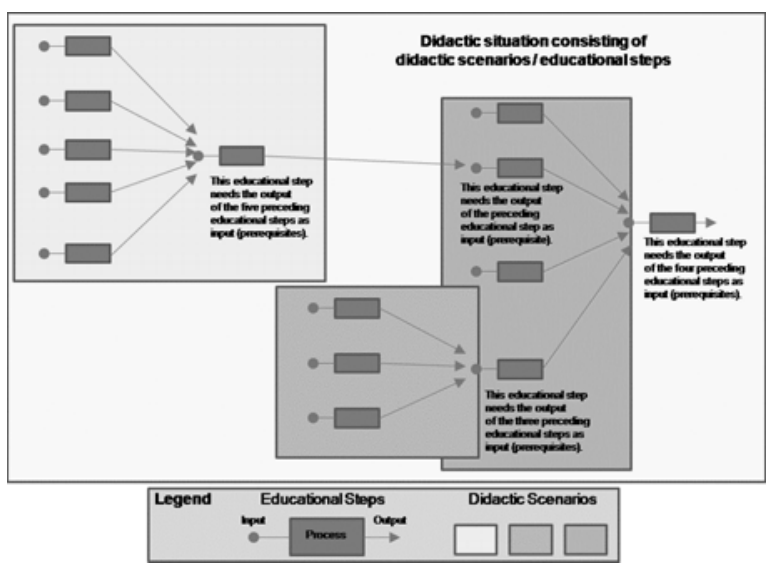

Fig. 2 Sequential steps in an educational process

A solution for this problem of quantity may be to create learnflow templates for the individual acts as models that can and should be reused, and to combine these into prototype learning paths by means of so-called learning patterns [2]. The number of learnflow templates can be reduced by systematising and combining them according to an appropriate formula. The basic idea here is that the learnflow templates can be viewed through the theatre prism mentioned above where they appear as plays with their acts and scenes, and bear a particular resemblance to Commedia dell'Arte, which proceeds as a fixed series of prescribed scenes, in which the same roles come up over and over again in the same sequences. These scenes, roles and the corresponding learning environment, composed of learning materials and services, can be implemented in the same way as software building blocks in object-oriented design and then made available in libraries. The authors are currently conducting research into this. From our present-day perspective this research can most probably be completed after the MOPEM project has finished.

In conclusion, it has been our aim in this paper to demonstrate the contexts and conditions for flexible learning paths that can be tailored to the individual. The idea of this kind of specialised path is to enable students to individualise their learning process and adjust it to suit their own needs. Here we have explained the backgrounds and given examples to show the concept of station learning as used in our courses. The basic idea here is to allow users to "freely" combine the learning content. This leads to the question of the multi-applicability of learning blocks in various learning contexts. The answers to this are not only interesting from the point of view of the feasibility of learning paths in terms of content and didactics, but also with an eye to the economic viability of E-Learning or Blended Learning Systems, which ultimately require technical implementation. We presented some initial remarks on designing a prototype Content Pool, which it would, however, only make sense to develop and implement in a follow-up project that takes into account the four dimensions - didactic, organisational, technical and economic.

\section{REFERENCES}

[1] TEB Education Corporation, MOPEM project proposal, EU Programme LEONARDO DA VINCI, Community Vocational Training Action Programme, Version 2006

[2] Tippe, U., and Haack, B.: Theorie und Praxis erfolgreicher Blended Learning-Konzepte, Wissenschaftliche Beiträge Heft 2006, p. 68-75, TFH Wildau, 2006.

[3] Scholl, M., Niemczik, C., and Brenstein, E.: Ready fo Blended Learning? - ein ganzheitlicher Ansatz; 5. Beckmann Kolloquium "Erfolgreiche Wirtschaftsentwicklung erfordert lebenslange Bildung", 6/7 June 2008, Wismar. See http://www,comble-project.eu for COMBLE's current state of development.

[4] Siebert, H.: Didaktisches Handeln in der Erwachsenenbildung - Didaktik aus konstruktivistischer Sicht, Ziel Verlag, 2006.

[5] Döring, K. W., and Ritter-Mamczek, B.: Lehren und Trainieren in der Weiterbildung, Beltz - Dt. Studien Verlag, $7^{\text {th }}$ ed., 1999.

[6] Herold, M., and Landherr, B.: SOL - Selbstorganisiertes Lernen. Ein systematischer Ansatz für Unterricht, 2 vol., from Schneider Verlag Hohengehren, paperback, 2005.

[7] Scholl, M.: IT-Didaktik: Selbstorganisiertes Lernen in der IT-Ausbildung und eLearning, Wissenschaftliche Beiträgen Heft 2004, p. 48-58, TFH Wildau, 2004.

[8] Klippert, H.: Kommunikations-Training, Übungsbausteine für den Unterricht, B66: Stationengespräch, Beltz Verlag, $9^{\text {th }}$ ed., 2002, p. 144.

[9] http://en.wikipedia.org/wiki/SCORM

[10]http://trac.edgewall.org/

[11] http://www.letsi.org/display/welcome/Home

[12]Klebl, M.: Nachhaltiges Design digitaler Lernmedien. Netzgestützte Bildungsprozesse mit IMS Learning Design, Studienverlag 2006, p. 152. 